\title{
Late results of antrectomy and vagotomy
}

\author{
ALAN C. B. DEAN ${ }^{1}$, HAROLD C. EDWARDS, AND A. I. MUNRO \\ From King's College Hospital, London
}

EDITORIAL SYNOPSIS Gastric acid secretion was absent in all patients tested 10 to 15 years after antrectomy and vagotomy. About half the patients followed-up had mild post-gastrectomy symptoms and some were anaemic. The series was closed in 1953 because it was thought that the mucosal atrophy after this operation might predispose to gastric carcinoma. So far, carcinoma has not developed in any case. Even so, other surgical procedures are now favoured because the followup shows that antrectomy and vagotomy does not greatly reduce the frequency of post-gastrectomy symptoms.

In recent years there has been renewed interest in the treatment of duodenal ulcer by antrectomy and vagotomy. The aim of the operation is to reduce gastric secretion to levels at which stomal ulceration will not occur, without producing the post-prandial symptoms or nutritional disturbances which may follow a high gastrectomy. An operation which involves only a limited gastrectomy may not appear radical anatomically but if it abolishes both the nervous and the hormonal phases of gastric secretion, then it certainly is radical physiologically and the long-term effects on the patient are of great importance in evaluating the operation. The purpose of this paper is to present the late results of a group of patients 10 to 15 years after antrectomy and vagotomy.

\section{OPERATIVE TECHNIQUE}

Vagotomy was performed through an upper abdominal midline incision as described by Austen and Edwards (1961). The antrum was removed by a one-third to onehalf gastrectomy. The lesser curve limit of the antrum was defined as that part of the distal stomach supplied by the right gastric artery, and the line of section made at an angle of $30^{\circ}$ from a horizontal line crossing the stomach at the point of anastomosis between the terminal branches of the left and right gastric arteries (Fig. 1). The stomach was anastomosed to the jejunum, the anastomosis being ante-colic in 29 patients and retro-colic in four. In one patient this was converted to a gastroduodenal anastomosis three years later because of bilious vomiting. There were no post-operative deaths. All operations were performed by the same surgeon (H.C.E.).

'Present address: Department of Surgical Science, University of Edinburgh.

'Present address: Department of Thoracic Surgery, St. Bartholomew's Hospital, London.

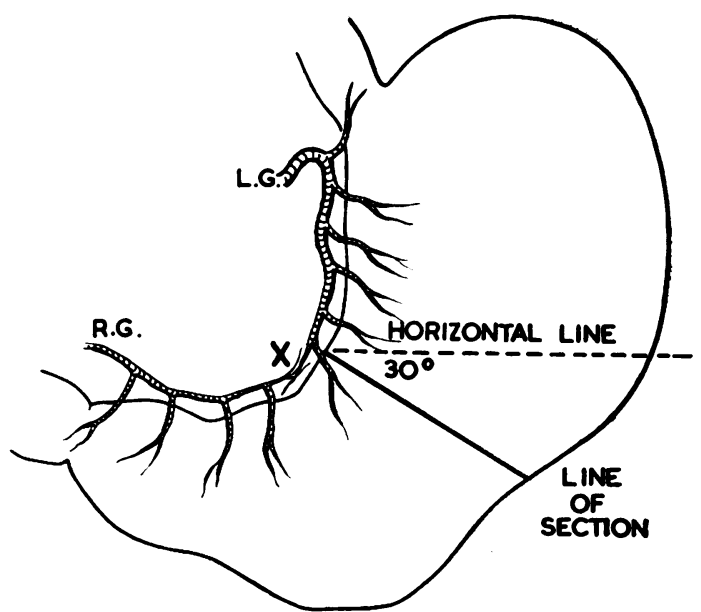

FIG. 1. Line of section of stomach at antrectomy

SERIES

Of the 33 patients who had a vagotomy and antrectomy for chronic duodenal ulcer between the years 1949 and 1953, 29 were male and four female. Their average age at the time of operation was 38.7 years, with a range of 25 to 54 years.

Twenty-seven of the 33 patients were traced and asked to attend for an interview. Some patients living at a distance were seen in their own homes. All interviews were carried out by one person (A.I.M.). The other six patients were not seen because three had left the country, one had died from carcinoma of the bronchus, one had severe senile dementia, and one could not be traced.

The result of the operation was assessed as follows: (a) Excellent, or completely symptom free; (b) good, occasional mild symptoms not interfering with daily life; 
(c) fair, moderate symptoms causing some disability but better than before operation; and $(d)$ failed, severe or incapacitating symptoms rendering the patient no better or even worse than before operation. Such symptoms were further analysed for the relative incidence of dumping symptoms, dyspepsia suggestive of recurrent ulceration, and diarrhoea. Where possible the patients' weight and haemoglobin were measured and a chest radiograph was taken.

Later the patients were asked to report again for a test of gastric secretion. The augmented histamine test of Kay (1953) was used. With the patient fasting a radio-opaque tube was carefully positioned in the gastric remnant under radiological control. Basal secretion was collected by continuous suction with frequent checking for one hour, 20 minutes before the end of which time $50 \mathrm{mg}$. of mepyramine maleate was given by intramuscular injection. At the end of the basal hour, $0.04 \mathrm{mg} / \mathrm{kg}$. of histamine acid phosphate was injected subcutaneously and the gastric secretion was collected in quarter-hour samples by the same method. The acid was estimated by titration against $\mathrm{N} / 50 \mathrm{NaOH}$ using screened methyl orange as indicator and acid output expressed as mEq. free $\mathrm{HCl}$ per hour. Pepsin was estimated by the method of Hunt (1948).

\section{RESULTS}

Of the 27 patients interviewed, 13 had an excellent result, 13 a good result, and one a fair result. There were no patients in the 'failed' category. Six of the patients in the 'good' category had occasional regurgitation or vomiting after certain foods or very large meals, five patients had occasional mild dumping attacks, and two had infrequent mild attacks of diarrhoea.

One patient has had two episodes of melaena nine years and 12 years after operation. After the second melaena a barium meal examination was thought to show a stomal ulcer in the efferent loop but another barium meal two months later was normal: his augmented histamine test showed achlorhydria. He has been classified as a fair result although he is well apart from occasional mild diarrhoea.

Haemoglobin estimations were obtained in 19 patients. In five it was less than $10.2 \mathrm{~g} . \%(70 \%)$, the lowest being $7.6 \mathrm{~g} . \%(52 \%)$. These five patients all had iron-deficiency anaemia and all responded to oral iron. One further patient with a normal haemoglobin concentration had been treated elsewhere with iron following a clinical diagnosis of anaemia.

In 16 patients body weight at follow-up had increased by an average of $10.8 \mathrm{lb}$. compared with the pre-operative weight. In four patients, weight had not changed, and in the remaining seven patients an average weight loss of $8.7 \mathrm{lb}$. had occurred. Five of these patients considered that, as a result of their ulcer diet, they had been overweight before their operation and were now nearer their ideal weight.
Weight gains and losses were evenly distributed between the patients with 'excellent' and 'good' results.

There were no new cases of pulmonary tuberculosis following vagotomy and antrectomy but two patients developed carcinoma of the bronchus, one dying from the disease. The other remains well three and a half years after resection of the carcinoma. If the age of this group and the number of smokers are considered we do not feel that two cases of carcinoma of the bronchus are outside the limits of probability.

\section{GASTRIC SECRETION}

Thirteen of the 27 patients in the series attended for an augmented histamine test. All 13 had a histaminefast achlorhydria: there was no free acid in the basal secretion nor after histaminestimulation. Secretion of pepsin was absent or minimal. In three patients there was no detectable peptic activity in the gastric juices before or after histamine stimulation. In six patients insignificant amounts of pepsin were secreted, an average of 6 units in the basal hour and 10 units in the histamine-stimulated hour. In the remaining four patients volumes were insufficient to perform a satisfactory assessment.

\section{DISCUSSION}

The combination of antrectomy with vagotomy is designed to avoid stomal ulceration by achieving the maximum reduction in gastric secretion. The patients in this series tested by the augmented histamine test all had achlorhydria 10 to 15 years after operation. A very high incidence of achlorhydria is reported in other series (Palumbo and Sharpe, 1965). However, Gillespie, Clark, Kay, and Tankel (1960)found some free acid in each of five patients investigated by the augmented histamine test soon after antrectomy and vagotomy. Two of these patients were tested again some months later, when the secretion had declined to only $0.07 \mathrm{mEq}$. of free acid in one patient and the other had achlorhydria. Similarly, Smithwick (1957) found that $14 \%$ of his patients had some free acid in the gastric juice when tested up to two years after operation, but when the tests were repeated between two and six years after operation this proportion had fallen to $4 \%$. These findings suggest that the secretory capacity of the stomach, already greatly reduced by operation, continues to decline with the passage of time until the state of achlorhydria is reached.

In normal people a steady decline in gastric secretion is found with increasing age (Levin, Kirsner, and Palmer, 1951; Baron, 1963) and this is presumably associated with the increasing incidence 
of gastritis found in the stomachs of older people. Ragins and Dittbrenner (1965) found moderate to severe gastritis in biopsies of the body mucosa in $53 \%$ of a group of normal patients whose average age was 59 and age correlated well with the severity of the gastritis. Similar changes are present in the antral mucosa of duodenal ulcer patients, especially in older patients and in those with a long history of ulcer (Dean and Mason, 1965). Severe atrophic gastritis is usually found in stomachs removed for benign gastric ulcer and Mason (1965) has found surface carcinoma in $10 \%$ of 78 partial gastrectomy specimens removed for benign gastric ulcer.

Helsingen and Hillestad (1956) found an increased incidence of gastric carcinoma in patients who had had a standard partial gastrectomy for benign gastric ulcer, but not in patients operated on for duodenal ulcer. However, if the gastric mucosa in duodenal ulcer patients undergoes a similar atrophic process to that of the gastric ulcer patients this freedom from gastric cancer may not be absolute, and an operation which produces complete achlorhydria might conceivably predispose to the development of cancer of the stomach. It was for this reason that antrectomy and vagotomy was abandoned in this charge in 1953. It was reassuring to find that 10 to 15 years after operation no patient had developed gastric cancer, but the numbers are not large enough nor is the follow-up long enough to be certain that there is no risk of this occurring, since cancer of the gastric remnant has been recorded up to 40 years after gastrectomy (Freedman and Berne, 1954).

In this series the results of the operation were satisfactory, all but one of the patients being classified as having an excellent or good response. However, the limited gastrectomy employed does not completely prevent the occurrence of post-gastrectomy symptoms. Goligher, Pulvertaft, and Watkinson (1964) found no significant difference in the incidence of these symptoms between groups of patients treated by standard gastrectomy, antrectomy and vagotomy, or vagotomy and gastroenterostomy. It is possible that the incidence of mild post-prandial discomfort might be reduced by using a Billroth 1 type of anastomosis instead of the antecolic Polya type em- ployed in this series. At least it can be said that the achlorhydria induced by the operation in our patients has not, so far, been accompanied by any gross metabolic deficiency.

In conclusion, the desirability of producing achlorhydria in an effort to avoid recurrent ulceration must remain a matter of opinion. Our results do not suggest that achlorhydria carries any serious side effects up to 10 to 15 years after operation, but this must still be considered a matter for much longer follow-up surveys. We believe that recurrent ulceration is a less serious disability than troublesome postgastrectomy symptoms and since antrectomy and vagotomy does not greatly affect the incidence of such symptoms, we have seen no reason to reintroduce this operation.

\section{REFERENCES}

Austen, W. G., and Edwards, H. C. (1961). A clinical appraisal of the treatment of chronic duodenal ulcer by vagotomy and gastric drainage operation. Gut, 2, 158-162.

Baron, J. H. (1963). Studies of basal and peak acid output with an augmented histamine test. Ibid., 4, 136-144.

Dean, A. C. B., and Mason, M. K. (1965). Unpublished observations.

Freedman, M. A., and Berne, C. J. (1954). Gastric carcinoma of gastro-jejunal stoma. Gastroenterology, 27, 210-217.

Gillespie, I. E., Clark, D. H., Kay, A. W., and Tankel, H. I. (1960). Effect of antrectomy, vagotomy with gastrojejunostomy, and antrectomy with vagotomy on the spontaneous and maximal gastric acid output in man. Gastroenterology, 38, 361-367.

Goligher, J. C., Pulvertaft, C. N., and Watkinson, G. (1964). Controlled trial of vagotomy and gastro-enterostomy, vagotomy and antrectomy, and subtotal gastrectomy in elective treatment of duodenal ulcer: interim report. Brit. med. J., 1, 455-460.

Helsingen, N., and Hillestad, L. (1956). Cancer development in the gastric stump after partial gastrectomy for ulcer. Ann. Surg., 143, 173-179.

Hunt, J. N. (1948). A method for estimating peptic activity in gastric contents. Biochem. J., 42, 104-109.

Kay, A. W. (1953). Effect of large doses of histamine on gastric secretion of $\mathrm{HCl}$. Brit. med. J., 2, 77-80.

Levin, E., Kirsner, J. B., and Palmer, W. L. (1951). A simple measure of gastric secretion in man: comparison of one hour basal secretion, histamine-secretion and 12 hour nocturnal gastric secretion. Gastroenterology, 19, 88-98.

Mason, M. K. (1965). Surface carcinoma of the stomach. Gut, 6, 185-193.

Palumbo, L. T., and Sharpe, W. S. (1965). Distal antrectomy with vagectomy. Arch. Surg., 91, 684-689.

Ragins, H., and Dittbrenner, M. (1965). Intracellular enzymatic histochemistry of the human stomach with special reference to atrophic gastritis. Gut, 6, 357-363.

Smithwick, R. H. (1957). Conservative gastric resection combined with vagotomy. Surgery, 41, 344-346. 